\title{
Joint predictability of health related quality of life and leisure time physical activity on mortality risk in people with diabetes
}

Chia-Lin Li $i^{1,2}$, Hsing-Yi Chang ${ }^{3^{*}}$, Chih-Cheng Hsu ${ }^{3}$, Jui-fen Rachel Lu ${ }^{1,2}$ and Hsin-Ling Fang ${ }^{3}$

\begin{abstract}
Background: Reduced health related quality of life (HRQOL) has been associated with increased mortality in individuals with diabetes. In contrast, increased leisure time physical activity (LTPA) has been associated with reduced mortality. The aim of this study was to investigate the combined relationship of HRQOL and LTPA on mortality and whether high levels of LTPA are associated with reduced risk of mortality in adults with diabetes and inferior HRQOL.
\end{abstract}

Methods: We analyzed data from a national sample of adults (18 years or older) with self-reported physiciandiagnosed diabetes, who participated in the 2001 National Health Interview Survey in Taiwan $(N=797)$. A total of 701 participants had complete Short Form 36 (SF-36) and LTPA data and were followed from 2002 to 2008. Participants were divided into 3 groups based on their LTPA: (1) a regularly active group who reported 150 or more min/week of moderate-intensity activity; (2) an intermediately active group who reported engaging in LTPA but did not meet the criterion for the "regular" category; and (3) an inactive group who reported no LTPA. The physical component summary (PCS) and mental component summary (MCS) scores were dichotomised at the median (high vs. low) (PCS = 45.11; MCS = 47.91). Cox proportional-hazards models were used to investigate associations between baseline characteristics and mortality.

Results: After 4,570 person-years of follow-up, 121 deaths were recorded and the crude mortality rate was 26.5 per 1,000 person-years. Both PCS scores and LTPA were significant predictors of mortality, whereas no significant relationship was observed between MCS and mortality. After adjustment for other factors, participants with low PCS who reported no LTPA had a hazard ratio (HR) for mortality of $4.49(95 \% \mathrm{Cl}=[2.15-9.36])$. However, participants with low PCS who were active (including intermediate and regular LTPA) had a HR for mortality of $1.36(95 \% \mathrm{Cl}=[0.64$ 2.92]).

Conclusions: Our results show a significantly increased mortality risk of diabetes associated with reduced HRQOL in individuals who report no LTPA. Engaging in LTPA may be associated with improved survival in participants with diabetes with poor self-rated physical health status.

Keywords: Diabetes, Health related quality of life, Leisure time physical activity, Mortality, Taiwan

\footnotetext{
* Correspondence: hsingyi@nhri.org.tw

${ }^{3}$ Division of Preventive Medicine and Health Service Research, Institute of Population Health Sciences, National Health Research Institutes, \#35, Keyan Road, A3223, Zhunan town, Maoli 350, Taiwan

Full list of author information is available at the end of the article
} 


\section{Background}

Subjective assessment of health related quality of life (HRQOL) is an important health outcome not only because it captures a person's perception of their overall health status, but also because it can inform resource allocation decisions. Recent research demonstrates that HRQOL is an independent predictor of mortality in people with diabetes [1-4]. Our previous research has also found that a self-perceived negative profile on the physical health domains of HRQOL in people with diabetes can predict those who are at higher risk for hospital admission even after taking into account known risk factors [5]. These findings highlight that the association between reduced HRQOL and further adverse outcomes has been understudied and that HRQOL has great potential value as a clinical marker that could be used to identify individuals with diabetes who are at higher risk of adverse outcomes and who therefore require more care.

HRQOL in people living with diabetes has been shown to be negatively influenced by diabetes-specific attributes, including higher glycosylated haemoglobin level, the presence of diabetes complications, and the severity of diabetes symptoms [6-10]. These diabetes-specific attributes are also known to be associated with an increased risk of mortality in people with diabetes [11-14]. Adequate physical activity is considered to be one of the most important self-care behaviours for glycemic control and the prevention of vascular events in people with diabetes [15]. Prior cross-sectional studies of adults with diabetes have demonstrated that increased leisure time physical activity (LTPA) is significantly associated with better HRQOL [16] and increased LTPA has been linked to a lower risk of mortality in individuals with diabetes [15,17]. However, prior studies exploring the relationship between HRQOL and mortality in individuals with diabetes have not controlled for LTPA. It is still not clear whether the relationship between reduced HRQOL and increased mortality remains among those individuals with diabetes who engage in higher levels of LTPA. Clarifying the association between LTPA and mortality in people with diabetes who have reduced HRQOL is particularly important because it may help in the design of intervention strategies.

In view of these considerations, we have analyzed data from a 7-year prospective study of a national sample of adults with diabetes in Taiwan. The aims of the present study were two-fold. First, we investigated whether HRQOL remained an independent predictor of mortality in adults with diabetes after controlling for LTPA. Second, we explored the combined associations of HRQOL and LTPA on mortality in order to examine whether higher levels of LTPA were associated with reduced risk of mortality in adults with diabetes with inferior HRQOL.

\section{Methods}

\section{Study population}

This was a prospective study involving participants in the 2001 National Health Interview Survey (NHIS) in Taiwan. The sample design of the NHIS has been described in detail previously $[18,19]$. In brief, a representative sample was drawn from the National Registry Database via multistage stratified sampling. The survey obtained ethical approval from the Institutional Review Board of the National Health Research Institutes. All study participants provided informed consent. The original sample comprising 22,121 participants (response rate; $94.2 \%$ ), can be treated as a simple random sample (SRS). Out of 16,137 participants aged 18 years or older, 797 reported physician-diagnosed diabetes. The crude prevalence of diabetes of adults aged 18 years or older was therefore $4.94 \%$ (797/16137), which does not include individuals with undiagnosed diabetes. Thus, the prevalence of diabetes (4.94\%) is likely to be underestimated and we may not be able to generalize our findings to individuals with undiagnosed diabetes. The agreement between self-reported physician-diagnosed diabetes and confirmed diabetes was very good [18]. Of these potential participants, we excluded 93 individuals with incomplete data regarding their health-related quality of life or leisure-time physical activity and 3 individuals who had died by the end of 2001, leaving 701 eligible participants for the analysis. The study cohort was followed until December 31, 2008, via personal identification numbers in the computerized data files of the National Register of Deaths. We compared the characteristics of study participants who were included $(\mathrm{N}=701)$ versus those who were excluded due to incomplete data $(\mathrm{N}=93)$ in order to assess the degree of respondent bias.

\section{Measures}

This study used the Taiwanese version of the SF-36, which was validated and has been shown to have good psychometric properties in a representative nationwide sample [20]. The SF-36 questionnaire has 36 items divided into eight dimensions (i.e., physical function, role limitations due to physical health problems, bodily pain, general health perceptions, vitality, social function, role limitations due to emotional problems, and mental health). Lower scores indicate poorer HRQOLs. The physical component summary (PCS) and the mental component summary (MCS) are aggregated from z-score transformations of the eight dimensions and then standardized to a mean of 50 and a standard deviation of 10 [21].

In this study, participation in LTPA was assessed first by asking respondents to reply "yes" or "no" to the question: "Have you engaged in any kind of leisure activity in the previous two weeks?" Those individuals replying "yes" to the question were asked to categorize these 
activities (up to three) according to a list of predefined typical leisure activities in this population. These activities included walking leisurely, jogging or race walking, swimming, traditional Chinese exercise, sports, aerobics, folk dancing, bicycling, mountain climbing, weightlifting and walking up stairs. There was also an "other" option where participants could report any specific activities which were not in the list. For each activity, the respondents also indicated the frequency and duration (hours and minutes) of the activity in the 2 weeks prior to the interview. Measures of physical activity were modified from the Nutrition and Health Survey in Taiwan [22,23]. The internal consistency of the questions for major types of exercise was 0.88 . The Kappa for the reported frequency and duration of activities ranged from 0.41 to 0.46 , implying acceptable validity and reproducibility. This measurement of LTPA has been used to examine the relationship between LTPA and self-rated health in Taiwanese adults with diabetes [24]. Physical activity measures using a similar format have been shown to be predictive of mortality in the general population and adults with diabetes $[17,25]$. In this study, the number of metabolic equivalents (METs) for each activity was calculated based on the report by Ainsworth et al. [26]. The participants were divided into 3 groups based on their LTPAs: (1) a regularly active group who reported $\geqq 150 \mathrm{~min} /$ week of moderate-intensity activity (METs values between 3 and 6); (2) an intermediately active group who reported engaging in LTPA but did not meet the criterion for the "regular" category; and (3) an inactive group who reported no LTPA.

Basic demographic information (such as age, sex, education, body weight and height) was obtained from the questionnaires. Body mass index (BMI) was calculated as weight (kilograms) divided by height squared (meters squared). Other factors associated with mortality among people with diabetes, including the duration of diabetes, the use of insulin, health behaviours (including smoking), and the presence of comorbidities, were also considered. The list of comorbidities included a history of heart disease, hypertension, dyslipidaemia, or stroke. For each disease (including diabetes), participants were asked whether the diagnosis had been confirmed by a medical professional. A small number of respondents did not answer all of the questions. For example, two participants had missing data for education. This information is available in the form of a footnote below Table 1.

\section{Statistical analysis}

We used the Student's $t$-test or Pearson's chi-square test to compare baseline characteristics between surviving and non-surviving participants. Cox proportional-hazards models were used to investigate the associations between
Table 1 Baseline characteristics of participants

\begin{tabular}{|c|c|c|c|c|}
\hline & Total & Deceased & Survived & P-value ${ }^{b}$ \\
\hline $\mathrm{N}$ & 701 & 121 & 580 & \\
\hline Age (years) & $60.6 \pm 0.44$ & $66.2 \pm 1.02$ & $59.4 \pm 0.47$ & $<0.001$ \\
\hline Sex (\% female) & 46.9 & 40.5 & 48.3 & 0.119 \\
\hline Education $^{\mathrm{a}}(\%)$ & & & & 0.001 \\
\hline$\geq 0$ and $<7$ years & 59.7 & 73.6 & 56.7 & \\
\hline$\geq 7$ years & 40.3 & 26.4 & 43.3 & \\
\hline Smoking (\% current) & 23.1 & 28.1 & 22.1 & 0.152 \\
\hline $\begin{array}{l}\text { Body mass index } \\
\left(\mathrm{kg} / \mathrm{m}^{2}\right)\end{array}$ & $25.1 \pm 0.16$ & $24.2 \pm 0.45$ & $25.2 \pm 0.17$ & 0.022 \\
\hline $\begin{array}{l}\text { Duration of } \\
\text { diabetes }^{\mathrm{a}} \text { (years) }\end{array}$ & $7.4 \pm 0.29$ & $11.6 \pm 0.85$ & $6.5 \pm 0.29$ & $<0.001$ \\
\hline $\begin{array}{l}\text { Using insulin }{ }^{a} \\
\text { (\% yes) }\end{array}$ & 14.2 & 21.5 & 12.7 & 0.011 \\
\hline $\begin{array}{l}\text { Heart disease }{ }^{a} \\
\text { (\% yes) }\end{array}$ & 24.9 & 35.8 & 22.5 & 0.002 \\
\hline $\begin{array}{l}\text { Hypertension }{ }^{\mathrm{a}} \\
\text { (\% yes) }\end{array}$ & 44.3 & 57.5 & 41.6 & 0.001 \\
\hline $\begin{array}{l}\text { Dyslipidaemia }(\% \\
\text { yes) }\end{array}$ & 37.9 & 32.4 & 39.0 & 0.204 \\
\hline Stroke $^{a}$ (\% yes) & 6.9 & 18.5 & 4.5 & $<0.001$ \\
\hline $\begin{array}{l}\text { Leisure time } \\
\text { physical activity (\%) }\end{array}$ & & & & 0.004 \\
\hline Inactive & 43.5 & 56.2 & 40.9 & \\
\hline Intermediate & 35.7 & 31.4 & 36.6 & \\
\hline Regular & 20.8 & 12.4 & 22.6 & \\
\hline \multicolumn{5}{|l|}{ SF-36 } \\
\hline Physical function & $75.1 \pm 1.01$ & $58.3 \pm 2.76$ & $78.6 \pm 1.01$ & $<0.001$ \\
\hline Role: physical & $59.7 \pm 1.72$ & $36.6 \pm 4.19$ & $64.5 \pm 1.83$ & $<0.001$ \\
\hline Bodily pain index & $69.3 \pm 0.97$ & $59.5 \pm 2.47$ & $71.3 \pm 1.03$ & $<0.001$ \\
\hline $\begin{array}{l}\text { General health } \\
\text { perceptions }\end{array}$ & $48.4 \pm 0.78$ & $41.0 \pm 1.93$ & $49.9 \pm 0.84$ & $<0.001$ \\
\hline Vitality & $57.6 \pm 0.83$ & $50.1 \pm 1.96$ & $59.2 \pm 0.91$ & $<0.001$ \\
\hline Social functioning & $77.9 \pm 0.91$ & $67.7 \pm 2.57$ & $80.1 \pm 0.93$ & $<0.001$ \\
\hline Role: emotional & $65.5 \pm 1.66$ & $54.5 \pm 4.30$ & $67.8 \pm 1.78$ & 0.005 \\
\hline Mental health index & $68.4 \pm 0.76$ & $65.2 \pm 1.89$ & $69.0 \pm 0.83$ & 0.060 \\
\hline $\begin{array}{l}\text { Physical component } \\
\text { summary }\end{array}$ & $40.3 \pm 0.54$ & $31.2 \pm 1.45$ & $42.2 \pm 0.55$ & $<0.001$ \\
\hline $\begin{array}{l}\text { Mental component } \\
\text { summary }\end{array}$ & $47.2 \pm 0.43$ & $46.5 \pm 1.11$ & $47.4 \pm 0.47$ & 0.450 \\
\hline
\end{tabular}

${ }^{\mathrm{a}}$ There were missing data.

${ }^{\mathrm{b}}$ Continuous variables were compared using the Student's $t$-test and shown as means \pm standard errors. Categorical variables were compared using Pearson's chi-square test and shown as a percentage of the total.

baseline characteristics and mortality. The proportional hazards assumption (tested using Schoenfeld residuals) was not violated. Hazard ratios (HRs) and 95\% confidence intervals $(95 \%$ CIs) for mortality were estimated. In order to examine whether adults with diabetes with inferior HRQOL, combined with higher levels of LTPA had a 
reduced risk of mortality, joint HRQOL and LTPA variables were created. PCS and MCS scores were dichotomised (high vs. low) at the median ( $\mathrm{PCS}=45.11$; $\mathrm{MCS}=47.91$ ). To study survival, Kaplan-Meier curves were plotted. We evaluated the discriminatory ability of PCS or LTPA or both to predict death by using the area under the receiver operating characteristic curve (C-statistics). We estimated $\mathrm{C}$-statistics with a macro using $\mathrm{R}$ language which was developed based on Harrell's C-statistics, and used these to evaluate the Cox regression models [27]. Apart from estimation of C-statistics, all analyses were conducted using SAS statistical software, version 9.1 (SAS Institute, Cary, NC), and SPSS statistical software, version 14.0 (SPSS, Chicago, IL., USA).

\section{Results}

Of 701 participants aged 18 or older with diabetes, 121 participants died between baseline and 7-year follow-up, giving a crude mortality rate of $17.2 \%$ (121/701). Table 1 compares baseline characteristics between survivors and non-survivors. Surviving participants were significantly younger, had higher education levels, had a shorter duration of diabetes, were less likely to use insulin, were less likely to have a history of heart disease, hypertension or stroke, were more likely to engage in LTPA, and had a higher mean BMI, PCS, and scores for each subscale of the SF-36 (except for the mental health index and MCS).
In Table 2 and Table 3, we present three models that explore the relationships among PCS, MCS, LTPA and mortality. Model 1 was adjusted for age, sex, education, smoking, BMI, the duration of diabetes, insulin use, and any history of heart disease, hypertension, dyslipidaemia or stroke. Model 2 was additionally adjusted for either PCS or LTPA. The adjusted HR for mortality for a low vs. high PCS score was $2.15(95 \% \mathrm{CI}=1.22-3.81)$ (Table 2, Model 1). This association remained statistically significant after additionally adjusting for LTPA (Table 2, Model 2). We then further categorized PCS and MCS scores by quartiles. After adjusting for other variables and LTPA, the adjusted HR for mortality for the lowest quartile group vs. the highest quartile group was 3.67 (95\% $\mathrm{CI}=1.61-8.37$ ). A low score in the MCS was not significantly associated with increased mortality after adjusting for the other variables and additionally adjusting for LTPA. The adjusted HRs for mortality were 0.40 (95\% CI $=0.22-0.71)$ in the intermediately active participants and $0.38(95 \% \mathrm{CI}=0.19-0.76)$ in the regularly active participants compared with inactive participants (Table 3, Model 1). These associations remained identical after additionally adjusting for PCS scores (Table 3, Model 2). The C-statistics for the models ranged from 0.675 to 0.793 , indicating good model prediction of mortality.

Table 4 compares baseline characteristics between those with high and low PCS scores after stratifying by level of LTPA. The results show that regardless of LTPA

Table 2 Adjusted hazard ratios (HRs) and 95\% confidence intervals (95\% Cls) for mortality according to SF-36 physical component summary (PCS) and mental component summary (MCS) scores in Taiwanese adults with diabetes

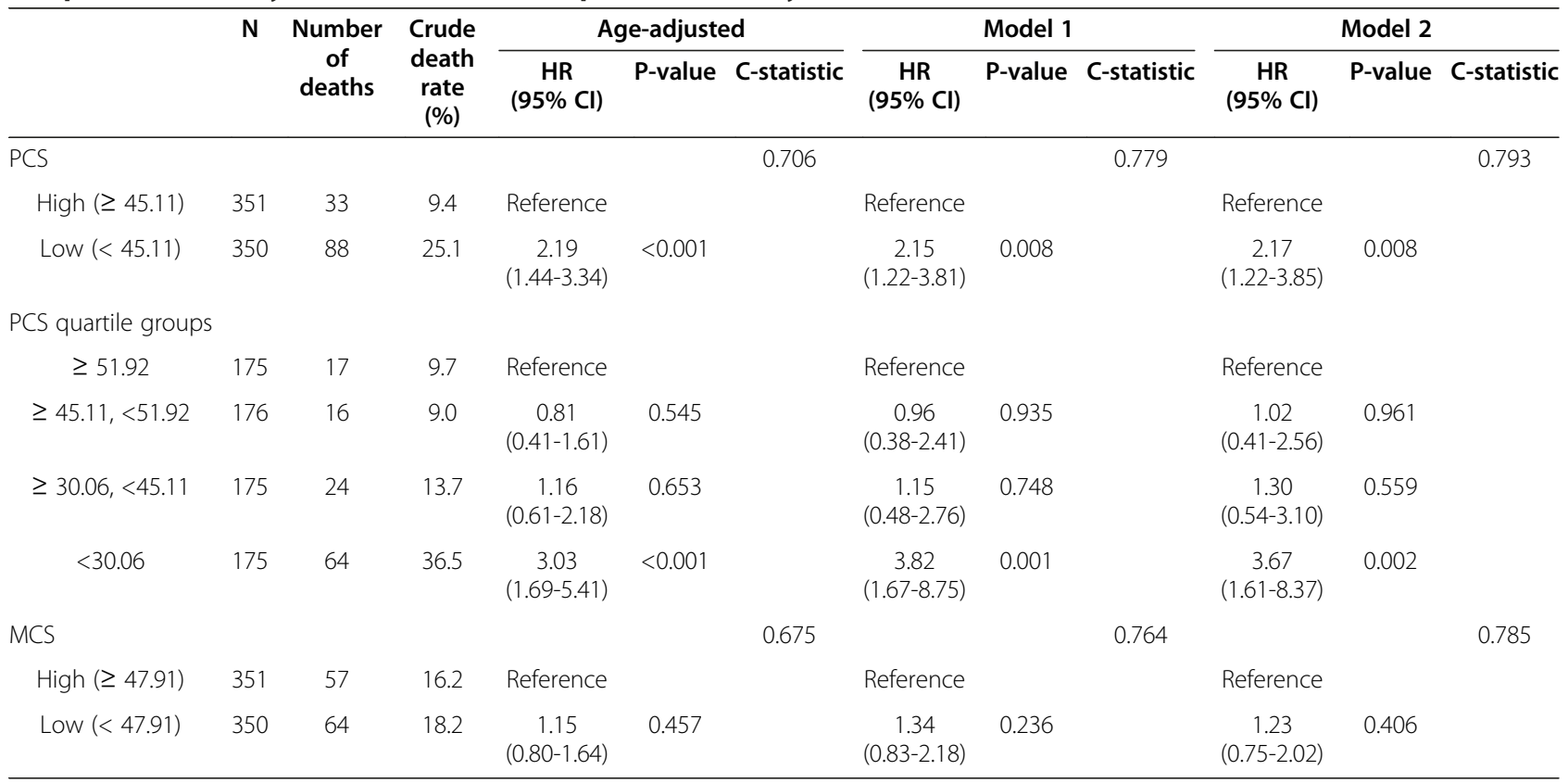


Table 3 Adjusted hazard ratios (HRs) and $95 \%$ confidence intervals (95\% Cls) for mortality according to levels of leisure time physical activity in Taiwanese adults with diabetes

\begin{tabular}{|c|c|c|c|c|c|c|c|c|c|c|c|c|}
\hline & \multirow[t]{2}{*}{$\mathrm{N}$} & \multirow{2}{*}{$\begin{array}{c}\text { Number } \\
\text { of } \\
\text { deaths }\end{array}$} & \multirow{2}{*}{$\begin{array}{c}\text { Crude } \\
\text { death } \\
\text { rate } \\
(\%)\end{array}$} & \multicolumn{3}{|c|}{ Age-adjusted } & \multicolumn{3}{|c|}{ Model 1} & \multicolumn{3}{|c|}{ Model 2} \\
\hline & & & & HR $(95 \% \mathrm{Cl})$ & $\mathrm{P}$-value & C-statistic & HR $(95 \% \mathrm{Cl})$ & P-value & C-statistic & $\mathrm{HR}(95 \% \mathrm{Cl})$ & P-value & C-statistic \\
\hline LTPA & & & & & & 0.697 & & & 0.784 & & & 0.793 \\
\hline Inactive & 305 & 68 & 22.2 & Reference & & & Reference & & & Reference & & \\
\hline \multirow[t]{2}{*}{ Intermediate } & 250 & 38 & 15.2 & 0.60 & 0.011 & & 0.40 & 0.002 & & 0.40 & 0.002 & \\
\hline & & & & $(0.40-0.89)$ & & & $(0.22-0.71)$ & & & $(0.23-0.72)$ & & \\
\hline \multirow[t]{2}{*}{ Regular } & 146 & 15 & 10.2 & 0.41 & 0.002 & & 0.38 & 0.006 & & 0.38 & 0.006 & \\
\hline & & & & $(0.23-0.71)$ & & & $(0.19-0.76)$ & & & $(0.19-0.76)$ & & \\
\hline
\end{tabular}

Model 1 was adjusted for age, sex, education, smoking, BMI, the duration of diabetes, insulin use, and any history of heart disease, hypertension, dyslipidaemia, or stroke. Model 2 was also adjusted for PCS.

level, participants with low PCS scores were significantly older, had lower educational levels, had a longer duration of diabetes, and had a greater prevalence of hypertension than participants with high PCS scores.

Figure 1 shows the survival curves for participants according to categories of levels of LTPA and scores for the PCS of the SF-36. We have further classified LTPA into active (including intermediate and regularly active) versus inactive groups. Table 5 shows the combined associations of LTPA and PCS with mortality. After adjusting for other variables, those who were inactive and had a low PCS score had significantly higher mortality $(\mathrm{HR}=4.49$; 95\% CI $=[2.15-9.36] ;$ P-value $<0.001)$ than those who were active and had a high PCS score.

Table 4 Characteristics of participants according to SF-36 physical component summary scores (PCS) and stratified by level of leisure time physical activity

\begin{tabular}{|c|c|c|c|c|c|c|c|c|c|}
\hline & \multicolumn{9}{|c|}{ Leisure time physical activity } \\
\hline & \multicolumn{3}{|c|}{ Inactive } & \multicolumn{3}{|c|}{ Intermediate } & \multicolumn{3}{|c|}{ Regular } \\
\hline & PCS & PCS & & PCS & PCS & & PCS & PCS & \\
\hline & (High) & (Low) & & (High) & (Low) & & (High) & (Low) & \\
\hline & & & P-value ${ }^{a}$ & & & P-value ${ }^{a}$ & & & P-value ${ }^{a}$ \\
\hline $\mathrm{N}$ & 148 & 157 & & 124 & 126 & & 79 & 67 & \\
\hline \multicolumn{10}{|l|}{ PCS } \\
\hline First quartile (Q1) & 49.1 & 17.3 & & 49.0 & 21.9 & & 50.0 & 23.7 & \\
\hline Second quartile (Q2) & 52.0 & 28.0 & & 51.6 & 31.2 & & 52.5 & 32.9 & \\
\hline Third quartile (Q3) & 54.3 & 36.2 & & 54.5 & 38.8 & & 54.4 & 40.2 & \\
\hline Age (years) & $53.8 \pm 0.83$ & $65.2 \pm 0.89$ & $<0.001$ & $59.3 \pm 1.03$ & $64.1 \pm 0.96$ & 0.001 & $57.7 \pm 1.25$ & $63.6 \pm 1.30$ & 0.001 \\
\hline Sex (\% female) & 39.9 & 54.8 & 0.009 & 50.8 & 54.0 & 0.617 & 30.4 & 43.3 & 0.106 \\
\hline Education & & & $<0.0001$ & & & 0.042 & & & $<0.001$ \\
\hline$\geq 0$ and $<7$ years & 57.5 & 80.3 & & 51.6 & 64.3 & & 27.8 & 59.7 & \\
\hline$\geq 7$ years & 42.5 & 19.7 & & 48.4 & 35.7 & & 72.2 & 40.3 & \\
\hline Smoking (\% current) & 37.2 & 22.3 & 0.004 & 19.4 & 14.3 & 0.284 & 22.8 & 17.9 & 0.468 \\
\hline Body mass index $\left(\mathrm{kg} / \mathrm{m}^{2}\right)$ & $24.9 \pm 0.30$ & $25.3 \pm 0.42$ & 0.491 & $25.2 \pm 0.37$ & $25.1 \pm 0.37$ & 0.768 & $25.1 \pm 0.39$ & $25.0 \pm 0.54$ & 0.899 \\
\hline Duration of diabetes (years) & $5.1 \pm 0.45$ & $9.0 \pm 0.71$ & $<0.001$ & $6.5 \pm 0.65$ & $9.1 \pm 0.74$ & 0.008 & $5.6 \pm 0.58$ & $9.1 \pm 1.11$ & 0.006 \\
\hline Using insulin (\% yes) & 12.2 & 22.6 & 0.017 & 8.9 & 14.3 & 0.181 & 6.4 & 17.9 & 0.032 \\
\hline Heart disease (\% yes) & 14.6 & 34.7 & $<0.001$ & 11.8 & 37.6 & $<0.001$ & 19.0 & 31.3 & 0.084 \\
\hline Hypertension (\% yes) & 34.0 & 51.0 & 0.003 & 33.9 & 57.6 & $<0.001$ & 36.7 & 55.2 & 0.025 \\
\hline Dyslipidaemia (\% yes) & 32.4 & 37.9 & 0.338 & 40.0 & 39.5 & 0.935 & 28.9 & 54.0 & 0.003 \\
\hline Stroke (\% yes) & 2.0 & 9.7 & 0.005 & 1.6 & 16.8 & $<0.001$ & 2.5 & 7.5 & 0.165 \\
\hline
\end{tabular}

${ }^{a}$ Continuous variables were compared using the Student's $t$-test and shown as means \pm standard errors. Categorical variables were compared using Pearson's chisquare test and shown as a percentage of the total. 


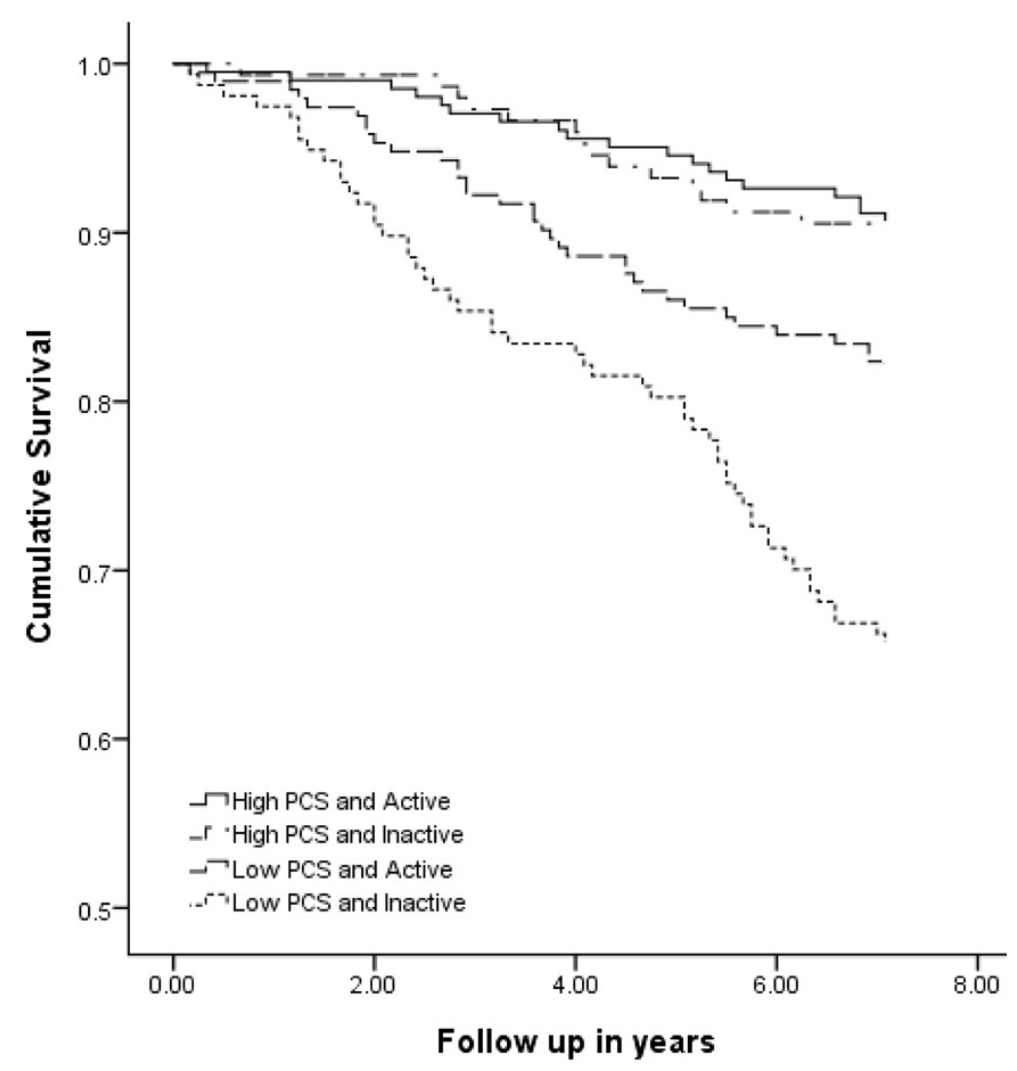

Figure 1 Survival curves according to categories of levels of LTPA and scores for the PCS of the SF-36.

\section{Discussion}

We demonstrated that both PCS scores and LTPA predict mortality in individuals with diabetes over 7 years of follow up. Furthermore, our study confirms that low PCS scores are associated with increased mortality in adults with diabetes, even after controlling for LTPA and other potential confounders. Our study further revealed that only participants who reported no LTPA with low PCS scores had significantly increased mortality compared to active participants with high PCS scores. Most importantly, there was no excess mortality risk associated with low PCS scores in participants who engaged in an intermediate or regular amount of leisure activity. Our joint analyses broaden our understanding of the benefits of engaging in LTPA, which may be associated with improved survival in participants with poor self-rated physical health status.

Table 5 Adjusted Hazard Ratios (HR) and 95\% Confidence Intervals (95\% Cl) for mortality by levels of leisure time physical activity and scores for the physical component summary (PCS) of the SF-36 among people with diabetes in Taiwan

\begin{tabular}{|c|c|c|c|c|c|c|c|}
\hline \multirow[t]{2}{*}{ Variable } & \multirow[t]{2}{*}{$\mathrm{N}$} & \multirow{2}{*}{$\begin{array}{l}\text { Number } \\
\text { of deaths }\end{array}$} & \multirow{2}{*}{$\begin{array}{c}\text { Crude } \\
\text { death rate (\%) }\end{array}$} & \multicolumn{2}{|c|}{ Age-adjusted $^{\mathrm{a}}$} & \multicolumn{2}{|c|}{ Multivariate adjusted $^{\mathbf{b}}$} \\
\hline & & & & HR $(95 \% \mathrm{Cl})$ & $\overline{P \text {-value }}$ & HR $(95 \% \mathrm{Cl})$ & P-value \\
\hline \multicolumn{8}{|l|}{ PCS and LTPA } \\
\hline High PCS and Active ${ }^{c}$ & 203 & 19 & 9.3 & Reference & & Reference & \\
\hline High PCS and Inactive & 148 & 14 & 9.4 & $1.25(0.62-2.50)$ & 0.537 & $1.31(0.51-3.35)$ & 0.578 \\
\hline Low PCS and Active ${ }^{c}$ & 193 & 34 & 17.6 & $1.65(0.94-2.91)$ & 0.083 & $1.36(0.64-2.92)$ & 0.426 \\
\hline Low PCS and Inactive & 157 & 54 & 34.3 & $3.38(1.98-5.75)$ & $<0.001$ & $4.49(2.15-9.36)$ & $<0.001$ \\
\hline C-Statistic & & & & 0.722 & & 0.792 & \\
\hline
\end{tabular}

${ }^{\mathrm{a}}$ Cox proportional hazard models were used to estimate the HR adjusted for age.

${ }^{\mathrm{b}} \mathrm{Cox}$ proportional-hazards models were used to estimate the HR adjusted for age, sex, education, smoking, BMI, the duration of diabetes, insulin use, and any history of heart disease, hypertension, dyslipidaemia, or stroke.

${ }^{c}$ Active group includes participants who were intermediately or regularly active. 
In this study, participants with low PCS scores were significantly older, had lower educational levels, had a longer duration of diabetes, and had a higher prevalence of hypertension than participants with high PCS scores, independent of LTPA level (Table 4). Previous studies have consistently shown that older people with diabetes have considerable physical impairment $[28,29]$. Our recent study has further shown that there is a gradient effect of functional decline on mortality in older adults with diabetes [30]. Glasgow et al. found that individuals diagnosed with diabetes for a greater number of years reported lower physical functioning (as assessed by the SF-20) than those with fewer years since diagnosis [31]. Longer diabetes duration is associated with an increased risk of exposure to chronic hyperglycaemia and an increased prevalence of cardiovascular disease such as hypertension, dyslipidaemia, and heart disease which may be associated with elevated mortality risk [14]. In a prospective cohort study, de Visser et al. found that a decreased score on the dimension of physical functioning (as assessed by the RADN-36) in individuals with type 2 diabetes is associated with short-term onset of cardiovascular disease [32]. Prior research has also found that patients with diabetes who report more bodily pain and poor physical functioning (as assessed by the SF-36) and poorer self-reported overall health are more likely to have an elevated glycosylated haemoglobin [33]. Most past research agrees that a higher glycosylated haemoglobin level, a measure of disease control in diabetes, is an important risk factor for mortality in people with diabetes. Diabetes complications such as coronary artery disease have a significant negative impact on the physical domains of HRQOL (as assessed by the SF-36) in individuals with diabetes [10]. These abovementioned research findings could explain the possible mechanisms behind our observed association between a reduced score on the physical aspect of HRQOL and increased mortality in individuals with diabetes.

Prior studies agree that increased LTPA is associated with reduced mortality in individuals with diabetes via several mechanisms. It has been suggested that engagement in regular physical activity may improve insulin sensitivity, glycemic control, cardiorespiratory fitness and physical function, as well as having favourable effects on hypertension and serum lipid profile [15,17,34-36]. Using a randomized controlled trial, Balducci et al. demonstrated that even mild aerobic exercise training, such as brisk walking, can modify the natural history of peripheral neuropathy in both type 1 and type 2 diabetes patients [37]. Thus, although factors such as an older age, long duration of diabetes, hyperglycaemia, cardiovascular disease, and diabetes complications may contribute to reduced scores on the physical health domains of HRQOL, the benefits of becoming physically active may translate into protective effects against their impacts on mortality. This is supported by our finding that in participants who engaged in intermediate or regular leisure time activity, no significant association was observed between low PCS scores and mortality (Table 5). Further investigation is needed to explore the underlying obstacles to engaging in LTPA and the underlying causes of increased mortality in adults with diabetes with inferior physical health domains of HRQOL. Moreover, intervention studies are needed to assess whether such individuals would benefit from interventions aimed at increasing their engagement in LTPA and improving survival.

Our finding that MCS scores did not predict increased mortality in individuals with diabetes is consistent with two previous studies [1,2]. In the first study carried out in the Zwolle region of the Netherlands, no association was observed between MCS scores and mortality in individuals with type 2 diabetes over a median follow-up period of 5.8 years [1]. However, the same investigators revisited the association between HRQOL and mortality after a longer follow-up period (almost 10 years), and found that low MCS scores were associated with higher mortality in patients with type 2 diabetes, suggesting that lower MCS scores only predict mortality after a longer follow-up period [38]. These findings may help explain why our results revealed no association between MCS scores and mortality in individuals with diabetes over only a 7-year follow-up period.

Our study has several limitations. Although the initial sample of 797 individuals with self-reported diagnosed diabetes is a nationally representative sample of adults aged 18 years or older with diagnosed diabetes, our analytic sample could be biased due to the included participants being limited to those who had complete data for HRQOL and LTPA. The comparison of characteristics between respondents who were included $(\mathrm{N}=701)$ and excluded due to incomplete data $(\mathrm{N}=93)$ from this study suggests that our sample could be biased towards individuals of younger age, with a shorter duration of diabetes, and who are less likely to be female, not smoking currently, and have a history of hypertension and stroke. Thus, some care should be taken when generalizing our results to the whole population. In addition, individuals with incomplete data for HRQOL or LTPA who were excluded from this study had a significantly higher mortality than individuals included in the study. Therefore, the observed crude mortality rate of 26.5 per 1,000 person-years may be an underestimate and the association of HRQOL and LTPA with mortality may also be underestimated. As we were still able to demonstrate a statistically significant association between HRQOL and LTPA and mortality despite this potential underestimation, it is likely that the association between HRQOL and LTPA and risk of mortality among adults with diabetes is substantial. 
Our analyses focused on LTPA because it was the only type of physical activity measure included in the 2001 NHIS and as a result, we may have underestimated the total physical activity levels of our participants. It is possible that some participants classified into the inactive group because they reported no LTPA, might be performing other types of physical activity such as housework leading to misclassification. The relationships between HRQOL and LTPA and mortality could differ by duration of diabetes and age. However, we were unable to investigate the impact of these factors on the association between HRQOL and LTPA and mortality as the small size of our sample did not enable us to stratify our participants by these characteristics when investigating the associations between HRQOL and LTPA and mortality. We did not control for clinically relevant variables such as glycated haemoglobin levels, urinary albumin-to-creatinine ratio, systolic blood pressure, serum creatinine, diabetes complications, and antidepressants. Therefore, residual confounding by these factors may have affected our results. As this study was an observational study, we cannot confirm the causal relationship between LTPA and HRQOL and mortality. It is very likely that the presence of severe health issues which precluded LTPA are also leading to reduced HRQOL and increased mortality. A sensitivity analysis excluding deaths that occurred during the first 2 years of follow-up would help correct for the impact of severe health issues at the start of the study, which could have an influence on both activity levels and HRQOL, in addition to an influence on mortality. After excluding deaths that occurred during the first 2 years of follow-up from the analysis, our finding of an association between increased LTPA and reduced mortality risk in adults with diabetes and inferior HRQOL remained unchanged. No data were available regarding the type of diabetes, and it is possible that HRQOL could vary based on diabetes type. However, only a small proportion $(<3 \%)$ of Taiwanese patients with diabetes have type 1 diabetes, and, therefore, it is likely that our results largely reflect the interrelationship between HRQOL, LTPA and the risk of mortality in patients with type 2 diabetes.

The major strength of our study is that we used a national sample of the Taiwanese population via the NHIS data and the National Register of Deaths. As this study was an observational study, we cannot rule out the possibility that the presence of poor self-rated HRQOL leads to lesser or no LTPA. However, we believe that this is unlikely to be the case in our study, because among participants with low PCS the percentage of those who reported regular leisure activities $(19.1 \%$; 67/350) was not significantly different from that in participants with high PCS $(22.5 \% ; 79 / 351)$. It is worthwhile noting that a great proportion of participants with diabetes reported no LTPA, regardless of either good or poor self-rated physical health (42.2\% vs. $44.9 \%)$. This result may reflect a general undervaluing of the merits of LTPA by individuals with diabetes. Our data further suggest that health care professionals should particularly target interventions aimed at improving survival towards adults with diabetes who are more likely to have reduced physical HRQOL, such as those who are older, have lower educational levels, have a longer duration of diabetes, and have a history of hypertension (Table 4).

\section{Conclusions}

To our knowledge, this is the first study to assess the interrelationship between physical health domains of HRQOL, LTPA and the risk of mortality in individuals with diabetes. Our results have important practical implications. Our finding of a C-statistic for the model based on joint PCS scores and LTPA variables and age of 0.722 suggests that the combined use of PCS scores and LTPA may be useful in identifying individuals with diabetes who are at higher risk of mortality in the absence of laboratory and clinical indicators. Our data suggest that health care professionals should pay careful attention to patient-reported HRQOL and levels of LTPA. Our results also suggest that health care professionals should be aware of the possible need for more care in individuals who report no LTPA to reduce the mortality risk of diabetes associated with reduced HRQOL in these persons. There is increasing recognition of the importance of patient-reported HRQOL as a part of individualized care in adults with diabetes. More research is needed to evaluate how HRQOL information can be used for health care planning and to inform resource allocation decisions. Our findings add to our understanding of the potential benefit of LTPA, even at levels not meeting diabetes-specific guidelines (i.e., 150 minutes of moderately intense activity per week), in terms of reducing the excess mortality associated with poor physical health. We hope our findings will stimulate further efforts to design and implement programs aimed at increasing LTPA, especially in individuals with diabetes who have poor self-rated physical health.

\section{Abbreviations \\ HRQOL: Health Related Quality Of Life; LTPA: Leisure-Time Physical Activity; NHIS: National Health Interview Survey; SF36: Short Form-36; PCS: Physical Component Summary; MCS: Mental Component Summary; HR: Hazard Ratios; Cl: Confidence Interval; METs: Metabolic Equivalents; BMI: Body Mass Index.}

Competing interests

None of the authors report any conflicts of interests.

\section{Authors' contributions}

CLL initiated the study, reviewed the data, and drafted and revised the manuscript. HYC conducted the NHIS survey, carried out the data analysis, reviewed the data, discussed the study, and revised the manuscript. $\mathrm{CCH}$ and JFRL reviewed the data, discussed the study and provided valuable 
comments on the manuscript. HLF carried out the data analysis, reviewed the data, and discussed the study. All authors reviewed the manuscript and approved the final version.

\section{Acknowledgements}

This study is based (in part) on data from the National Health Interview Survey Original Database provided by the Bureau of Health Promotion, the Department of Health and the National Health Research Institutes. The interpretation and conclusions contained herein do not represent those of the Bureau of Health Promotion, the Department of Health or the National Health Research Institutes. This study was supported (in part) by grants (NSC99-2410-H-182-007 and NSC100-2410-H-182-004-MY2) from the National Science Council of the Republic of China, Taiwan and a grant (EMRPD1A0871) from the Healthy Aging Research Center, Chang Gung University, Taiwan.

\section{Author details}

'Department of Health Care Management, College of Management, Chang Gung University, 259 Wen-Hwa 1st Road, Kwei-Shan, Tao-Yuan 333, Taiwan. ${ }^{2}$ Healthy Aging Research Center, Chang Gung University, 259 Wen-Hwa 1st Road, Kwei-Shan, Tao-Yuan 333, Taiwan. ${ }^{3}$ Division of Preventive Medicine and Health Service Research, Institute of Population Health Sciences, National Health Research Institutes, \#35, Keyan Road, A3223, Zhunan town, Maoli 350, Taiwan.

Received: 31 January 2012 Accepted: 16 January 2013

Published: 24 January 2013

\section{References}

1. Kleefstar N, Landman GW, Houweling ST, Ubink-Veltmaat L, Logtenberg SJ, Meyboom-de Jong B, Coyne JC, Groenier KH, Bilo HJ: Prediction of mortality in type 2 diabetes from health-related quality of life (ZODIAC-4). Diabet Care 2008, 31:932-933.

2. Hayashino Y, Fukuhara S, Akiba T, Akizawa T, Asano Y, Saito S, Kurokawa K: Low health-related quality of life is associated with all-cause mortality in patients with diabetes on haemodialysis: the Japan dialysis outcomes and practice pattern study. Diabet Med 2009, 26:921-927.

3. Clarke PM, Hayes AJ, Glasziou PG, Scott R, Simes J, Keech AC: Using the EQ-5D index score as a predictor of outcomes in patients with type 2 diabetes. Med Care 2009, 47:61-68.

4. McEwen LN, Kim C, Haan MN, Ghosh D, Lantz PM, Thompson TJ, Herman WH: Are health-related quality-of-life and self-rated health associated with mortality? insights from translating research into action for diabetes (TRIAD). Prim Care Diabetes 2009, 3:37-42.

5. Li CL, Chang HY, Lu JR: Health-related quality of life predicts hospital admission within 1 year in people with diabetes: a nationwide study from Taiwan. Diabet Med 2009, 26:1055-1062.

6. Chittleborough CR, Baldock KL, Taylor AW, Phillips PJ: Health status assessed by the SF-36 along the diabetes continuum in an Australian population. Qual Life Res 2006, 15:687-694.

7. Rubin RR, Peyrot M: Quality of life and diabetes. Diabetes Metab Res Rev 1999, 15:205-218.

8. Gulliford MC, Mahabir D: Relationship of health-related quality of life to symptom severity in diabetes mellitus: a study in Trinidad and Tobago. J Clin Epidemiol 1999, 52:773-780.

9. Wexler DJ, Grant RW, Wittenberg E, Bosch JL, Cagliero E, Delahanty L, Blasis MA, Meiqs JB: Correlates of health-related quality of life in type 2 diabetes. Diabetologia 2006, 49:1489-1497.

10. Lloyd A, Sawyer W, Hopkinson P: Impact of long-term complications on quality of life in patients with type 2 diabetes not using insulin. Value Health 2001, 4:392-400.

11. Dale AC, Midthjell K, Nilsen TI, Wiseth R, Vatten LJ: Glycaemic control in newly diagnosed diabetes patients and mortality from ischaemic heart disease: 20-year follow-up of the HUNT study in Norway. Eur Heart 2009, 30:1372-1377.

12. Otiniano ME, Markides KS, Ottenbacher K, Ray LA, Du XL: Self-reported diabetic complications and 7-year mortality in Mexican American elders: findings from a community-based study of five southwestern states. J Diabetes Complications 2003, 17:243-248.
13. Smith NL, Barzilay II, Kronmal R, Lumley T, Enquobahrie D, Psaty BM: New-onset diabetes and risk of all-cause and cardiovascular mortality: the cardiovascular health study. Diabet Care 2006, 29:2012-2017.

14. Spijkerman AM, Dekker JM, Nijpels G, Jager A, Kostense PJ, van Hinsbergh W, Bouter LM, Heine RJ, Stehouwer CD: Impact of diabetes duration and cardiovascular risk factors on mortality in type 2 diabetes: the Hoorn study. Eur J Clin Invest 2002, 32:924-930.

15. Hu G, Eriksson J, Barengo NC, Lakka TA, Valle TT, Nissinen A, Jousilahti P, Tuomilehto J: Occupational, commuting, and leisure-time physical activity in relation to total and cardiovascular mortality among Finnish subjects with type 2 diabetes. Circulation 2004, 110:666-673.

16. Li C, Ford ES, Mokdad AH, Jiles R, Giles WH: Clustering of multiple healthy lifestyle habits and health-related quality of life among U.S. adults with diabetes. Diabet Care 2007, 30:1770-1776.

17. Gregg EW, Gerzoff RB, Caspersen CJ, Williamson DF, Narayan KM: Relationship of walking to mortality among US adults with diabetes. Arch Intern Med 2003, 163:1440-1447.

18. Chang HY, Chiou CJ, Lin MC, Lin SH, Tai TY: A population study of the selfcare behaviors and their associated factors of diabetes in Taiwan: results from the 2001 national health interview survey in Taiwan. Prev Med 2005, 40:344-348.

19. Shih YT, Hung YT, Chang HY, Liu JP, Lin HS, Chang MC, Chang FC, Hsiung CA, WU SL: The design, contents, operation and the characteristics of the respondents of the 2001 national health interview survey in Taiwan. Taiwan J Public Health 2003, 22:419-430.

20. Lu JF, Tseng HM, Tsai YJ: Assessment of health-related quality of life in Taiwan (I): development and psychometric testing of SF-36 Taiwan version. Taiwan J Public Health 2003, 22:501-511.

21. Ware JE: SF-36 physical \& mental health summary scales: a user's manual. Boston: Quality Metric; 1997.

22. Lan TY, Chang HY, Tai TY: Relationship between components of leisure physical activity and mortality in Taiwanese older adults. Prev Med 2006, 43:36-41.

23. Pan WH, Hung YT, Shaw NS, Lin W, Lee SD, Chiu CF, Lin MC, Chen SY, Hong CM, Huang TY, Chang HY, Tu SH, Chang YH, Yeh WT, Su SC: Elderly nutrition and health survey in Taiwan (1999-2000): research design, methodology and content. Asia Pac J Clin Nutr 2005, 14:203-210.

24. Li CL, Lai YC, Tseng CH, Lin JD, Chang HY: A population study on the association between leisure time physical activity and self-rated health among diabetics in Taiwan. BMC Public Health 2010, 10:277.

25. Pereira MA, FitzerGerald SJ, Gregg EW, Joswiak ML, Rvan WJ, Suminski RR, Utter AC, Zmuda JM: A collection of physical activity questionnaires for health-related research. Med Sci Sports Exerc 1997, 29:S1-S205.

26. Ainsworth BE, Haskell WL, Whitt MC, Irwin ML, Swartz AM, Strath SJ, O'Brien WL, Bassett DR Jr, Schmitz KH, Emplaincourt PO, Jacobs DR Jr, Leon AS: Compendium of physical activities: an update of activity codes and MET intensities. Med Sci Sports Exerc 2000, 32:S498-S504.

27. Harrell FE, Lee KL, Mark DB: Multivariable prognostic models: issues in developing models, evaluating assumptions and adequacy, and measuring and reducing errors. Stat Med 1996, 15:361-387.

28. De Rekeneire N, Resnick HE, Schwartz AV, Shorr RI, Kuller LH, Simonsick EM, Vellas B, Harris TB: Diabetes is associated with subclinical functional limitation in nondisabled older individuals: The health, aging, and body composition study. Diabet Care 2003, 26:3257-3263.

29. Rodríguez-Saldaña J, Morley JE, Reynoso MT, Medina CA, Salazar P, Cruz E, Torres AL: Diabetes mellitus in a subgroup of older Mexicans: prevalence, association with cardiovascular risk factors, functional and cognitive impairment, and mortality. J Am Geriatr Soc 2002, 50:111-116.

30. Li CL, Chang HY, Shyu YIL: The excess mortality risk of diabetes associated with functional decline in older adults: results from a 7-year follow-up of a nationwide cohort in Taiwan. BMC Public Health 2011, 11:953.

31. Glasgow RE, Ruggiero L, Eakin EG, Dryfoos J, Chobanian L: Quality of life and associated characteristics in a large national sample of adults with diabetes. Diabet Care 1997, 20:562-567.

32. de Visser CL, Bilo HJG, Groenier KH, de Visser W, Meyboom-de B: The influence of cardiovascular disease on quality of life in type 2 diabetes. Qual Life Res 2002, 11:249-261.

33. Sinnott C, Rogers MA, Lehmann D, Weinstock RS: Bodily pain, poor physical functioning, and poor glycemic control in adults with diabetes. Diabet Care 2005, 28:1534. 
34. Boulé NG, Haddad E, Kenny GP, Wells GA, Sigal R: Effects of exercise on glycemic control and body mass in type 2 diabetes mellitus: a meta-analysis of controlled clinical trials. JAMA 2001, 286:1218-1227.

35. Wei M, Gibbons LW, Kampert JB, Nichaman MZ, Blair SN: Low cardiorespiratory fitness and physical inactivity as predictors of mortality in men with type 2 diabetes. Ann Intern Med 2000, 132:605-611.

36. Colberg SR, Sigal RJ, Fernhall B, Regensteiner JG, Blissmer BJ, Rubin RR, Chasan-Taber L, Albright AL, Braun B, American College of Sports Medicine, American Diabetes Association: Exercise and type 2 diabetes. The American college of sports medicine and the American diabetes association: joint position statement executive summary. Diabet Care 2010, 33:2692-2696.

37. Balducci S, lacobellis G, Parisi L, Di Biase N, Calandriello E, Leonetti F, Fallucca F: Exercise training can modify the natural history of diabetic peripheral neuropathy. J Diabetes Complications 2006, 20:216-223.

38. Landman GW, Van-Hateren KJ, Kleefstra N, Groenier KH, Gans RO, Bilo HJ: Health-related quality of life and mortality in a general and elderly population of patients with type 2 diabetes (ZODIAC-18). Diabet Care 2010, 33:2378-2382

doi:10.1186/1471-2458-13-67

Cite this article as: Li et al:: Joint predictability of health related quality of life and leisure time physical activity on mortality risk in people with diabetes. BMC Public Health 2013 13:67.

\section{Submit your next manuscript to BioMed Central and take full advantage of:}

- Convenient online submission

- Thorough peer review

- No space constraints or color figure charges

- Immediate publication on acceptance

- Inclusion in PubMed, CAS, Scopus and Google Scholar

- Research which is freely available for redistribution 